\title{
A Multi-scale Approach to Interculturalism: From Globalised Politics to Localised Policy and Practice
}

\author{
Ricard Zapata-Barrero ${ }^{1} \cdot$ Fethi Mansouri $^{2}$
}

Accepted: 24 May 2021/Published online: 10 July 2021

(c) The Author(s) 2021

\begin{abstract}
Interculturalism (IC) is presently discussed as a foundational basis for local public policy aimed at managing migration-related diversity within ethno-culturally plural societies, especially at the local level. Despite its increased saliency over the last decade, IC is neither theoretically new nor was it always intended for mere application in strictly city contexts of diversity. Rather, it has a global origin as a political basis for international relations and negotiations. In discussing these origins, this article has two main interrelated aims. Firstly, it provides an overview of the multi-scale approach of IC, with the purpose of disentangling analytically the different empirical bases where it can frame the diversity agenda. Secondly, it explores whether a lack of appreciation and awareness of this multi-scale orientation may affect IC's capacity to address the challenges of diversity governance at the local level. Methodologically, the article will undertake a textual analysis of a select number of leading documents framing its practice within the broader policy literature produced by the four main institutions that have advocated the intercultural approach within a global agenda. These are the United Nations Educational, Scientific and Cultural Organization (UNESCO) and United Nations University, on one hand, and the European Union and the Council of Europe on the other. The main findings show us the importance of a multi-scale thinking in diversity and IC studies, to avoid contributing to greater confusion in its applications.
\end{abstract}

Keywords Interculturalism · Intercultural dialogue $\cdot$ Global politics $\cdot$ Local policy $\cdot$ Diversity $\cdot$ City $\cdot$ Multi-scale analysis

Ricard Zapata-Barrero

ricard.zapata@upf.edu

1 Interdisciplinary Research Group on Immigration (GRITIM-UPF), Social and Political Sciences Department, Pompeu Fabra University, Barcelona, Spain

2 Alfred Deakin Institute for Citizenship and Globalization, Deakin University, Melbourne, Australia 


\section{Introduction}

Interculturalism (IC) is increasingly being invoked as a possible basis for policy strategies aimed at managing migration-related diversity within local ethnoculturally plural societies, especially at the local level (Cantle, 2012; Wood, 2004; Zapata-Barrero, 2017a). IC first emerged as a strategy to deal with conflicts related to indigenous people in particular in the context of Latin America. In most of these geographical origins of interculturalism, the seminal conflictbased approach to IC persists. For instance, IC continues to frame most diversity debates in Latin American countries (Solano-Campos, 2013, 2016; Tubino \& Sinnigen, 2013), where it is even recognised constitutionally in some jurisdictions as is the case in Mexico. This debate has also been happening in Canada (Lashta et al., 2016), particularly Quebec (Bouchard, 2015; Gagnon \& Iacovino, 2016), and Australia (Mansouri et al., 2017; Mansouri \& Lobo, 2011) since the 1990s and even earlier (Delafenetre, 1997). However, IC still needs to articulate its distinct voice in the context of the well-established multicultural grand narrative that has dominated various diversity management contexts (Meer et al., 2016; Levrau \& Loobuyck, 2018; Mansouri \& Modood, 2020), even if multiculturalism has come under severe scrutiny recently, losing some of its centrality as a key diversity policy paradigm (Zapata-Barrero, 2019a).

Although becoming increasingly salient over the last decade or so, IC as a mechanism for diversity management is not theoretically altogether new, even if its application to migration-related issues, as increasingly multi-ethnic societies grapple with the complex manifestations and implications of super-diversity, is somewhat novel (Elias et al., 2020; Vertovec, 2007). Indeed, IC has a more global origin in international relations and negotiations, as the below discussion on its application within various United Nations (UN) agencies will show. IC has also been used for interfaith dialogue and conflict resolution in ethnically and religiously divided territories and societies, for example, in the case of post-war Lebanon (Yazbeck Haddad \& Fischbach, 2015), Europe (Orton, 2016) and subSaharan Africa (Omotosho, 2014) and many other similar contexts. It has even been used as a strategy for region building within a broader Euro-Mediterranean partnership (Perini, 2020; Walton, 2012). This global orientation around political conflicts has been primarily constructed within international institutions with the purpose of direct application at inter-state and even inter-regional levels, rather than exclusively at intra-state local levels involving people-to-people interactions and exchanges. Therefore, it is not plausible to characterise the intercultural paradigm as a completely new intervention in the diversity management realm. What is emerging anew is its application to contemporary migration-related challenges that have been heightened in post-9/11 securitised agendas within societies that are increasingly transnational and super-diverse (Zapata-Barrero, 2019b).

The philosophical nucleus of IC as a policy lies in its emphasis on interpersonal contacts, interactions and cross-cultural engagement among people from different diversity category backgrounds, including different nationalities. At its root, IC presupposes "cultural exchange" and, therefore, by definition is a 
relational concept. This relational feature of the intercultural approach is being presented as a policy basis aimed at avoiding the socio-cultural consequences of a poorly managed or in some cases non-managed diversity situations. A lack of intercultural mindedness is probably one of the main shortcomings observed at present in contemporary multicultural societies, even if such concerns are not completely new. Ordinary people have always had difficulty joining the main course of history without directly suffering its consequences of injustice and inequality. Today, even if social class remains an important explanatory factor of the lived reality, with the onset of super-diversity, it is often interlinked with race, ethnicity and culture and other categories of difference, such as gender, religion, sexual orientation, age and education. This makes for a complex social and political mélange, which some authors have labelled as super-diversity (Vertovec, 2007) that presents both negative and positive potentialities.

In this sense, IC seems to exhibit two different but interrelated dimensions. The first being a reactive dimension emanating from a conflict-based approach and understood as a mechanism for reducing diversity-related conflicts. The second reflects a proactive approach with a transformative capacity, aimed at fostering new forms of citizenship identity and belonging decoupled from birth and origin and built on new framings of cohesion, social innovation and intergroup solidarity.

The original global agenda of IC was conceptually framed around a conflict-based approach to diversity and has mainly been approached as a political strategy for conflict prevention and conflict resolution. This is where the contemporary emphasis of IC on dialogue comes from, especially its conceptual linking to peace agendas, human rights and political stability. Against this background, IC is currently being advanced as a tool for driving dialogue and for achieving shared views and responsibilities in situations where relations between two or more parties display distant, opposing or irreconcilable views. As such, and viewed from an international relations perspective, the IC policy narrative has previously been constructed in a context of global civilisational clashes (Huntington, 1993) and regional ethno-religious conflicts, as is currently the case in the Mediterranean, parts of Asia and, most notably, across the Middle East and North Africa (Hashemi, 2016). It is through this set of conceptual and policy premises that IC started to penetrate migration and diversity studies in recent years (Zapata-Barrero, 2019a, p. 19) initially in Europe but increasingly internationally (Mansouri \& Modood, 2020). In 2008, the Council of Europe (CoE) launched its innovative Intercultural Cities (ICC) programme, which incorporated new applications (from global to local), new approaches (from politics to policies) and new interpretations of diversity (from a conflict-based to a resourcebased view of diversity). This has led, as will be discussed below, to a much more proactive role for IC within culturally and religiously plural societies. This new orientation of IC is characterised by a multi-scale approach to diversity governance and a multi-sectoral application in the context of everyday, lived diversity.

The purpose of this article, therefore, is twofold. Firstly, it seeks to provide an overview of this multi-scale approach to and application of IC, with the aim of disentangling analytically the different types of empirical bases and multi-scale situations through which IC can approach the diversity agenda. Secondly, to examine whether a lack of appreciation and awareness of this multi-scale orientation may 
undermine IC's capacity to proactively deal with the challenges of super-diversity governance at the local level.

Overall, this article contends that the shift in application of IC from the global to the local agenda reflects a change in its functional perception from a politics of conflict resolution and prevention (global sphere) to a policy (local sphere) of interpersonal contact and critical cross-cultural engagement. This presents IC not only as a political mechanism for state-to-state conflict resolution (at the global sphere), but also as a policy strategy to manage people-to-people relations in diverse settings. This vertical shift allows IC to contribute proactively to social cohesion agendas in diversity settings (at the local level). Furthermore, and in changing its sphere of application (from global to local) and public objective (from states and regions to people and migrants), IC retains much of the initial focus contained at the global level, such as conflict resolution and civilisational dialogue, but adds new dimensions that allow it to shift from reactive to proactive functionality. These analytical and functional distinctions are key to a better understanding and calibration of the current debates around IC's role in diversity management.

\section{Sources and Methods}

In order to examine this multi-scale orientation of IC, this article undertakes a textual analysis of a select number of key documents and policy papers from four prominent institutions. These four international institutions are chosen because they have played a leading role in championing the intercultural approach today. These are, in no preferential order, the UN Educational, Scientific and Cultural Organization (UNESCO) and UN University (UNU), on one hand, and the European Union (EU) and the $\mathrm{CoE}$, on the other. The key criteria for selecting and analysing particular documents from the broader body of policy literature pertain to how much they have shaped debates within these organisation and beyond as reflected in visibility and uptake within these institutions and beyond. Following the mainstream techniques of textual analysis of policy documents (Roe, 1994), we focus on the main narrative regularities. Whilst including exhaustive lists of quotes and excerpts is beyond the scope of this paper, we have carefully selected key content for analysis and inclusion in this paper that provide optimal illustrative examples of how IC has been approached. In pursuing this analysis of key IC and intercultural dialogue (ICD) policy literature, we acknowledge that "there is no such thing as a value-free policy: all policy has value-based intent" (Cardno, 2018, p. 624). It is for this reason that we have systematically undertaken to contextualise the analysis of this literature against the socio-political background within which they were produced. Our approach, therefore, is not a mere textual analysis of the language and meanings but also an examination of the politics and ideologies that have led to this intercultural turn.

The guiding question for our analysis relates to how IC has been conceptually understood, designed and implemented across different jurisdictions and within socio-political contexts. In doing so, the analysis also engages with the different notions and understandings of diversity and intercultural relations that IC/ICD is 
supposed to address, both as a mechanism for deliberation and as a strategy for intervention. Two initial standards define our textual analysis: (a) different manifestations and meanings of diversity and (b) how IC/ICD as a diversity governance strategy is conceptualised and contextually applied by different institutions to respond to particular notions of diversity. Although we use both IC and ICD, we make the following important distinctions. IC is the broader theoretical construct that refers to the conceptual, epistemological and theoretical normative assumptions behind the intercultural approach. ICD, on the other hand, has a more applied orientation as a deliberative tool for managing diversity-related "problems" and, in particular, conflict prevention within and across communities. ICD is often invoked as an applied tool at the global level, predominantly in a context of conflict resolution and prevention. Hereafter, in this article, all references to IC imply by extension its related concept of ICD unless otherwise specified.

\section{International Perspectives on IC's Approach to Diversity Governance}

Before engaging with our select textual analysis of key international policy literature in the intercultural approach pursued by leading international bodies, it is useful to offer some operational clarifications on the core terminology in this area. This article adopts a position that IC is primarily concerned with interpersonal contact, cross-cultural exchange and the capacity to challenge fixed views about cultures and worldviews. Within this general intercultural approach, the aim is to engender mutual respect, understanding, social inclusion and an attachment to shared values that enhance intercultural citizenship agendas (Zapata-Barrero, 2019a). Secondly, the intercultural idea is inherently multi-, inter- and trans-disciplinary (Elias \& Mansouri, 2020) and, therefore, is not consigned to any particular intellectual approach, even though it is increasingly linked to ideas of social cohesion, democratic citizenship and human rights (Elias \& Mansouri, 2020). Thirdly, leading international institutions have played and continue to play an important role in translating the core intercultural ideas into possible strategies and policies that promote the values of mutuality, exchange and respect. Therefore, when engaging with the key documents produced by these institutions, our analysis reflects the deeper philosophical assumptions underpinning the values associated with IC (Mansouri, 2017).

Approached in this manner, IC has been invoked in recent years by leading international organisations, most notably UNESCO and the CoE, as a new diversity governance tool in a changing socio-political context. Indeed, "promoting intercultural dialogue has been a priority for most international organisations for quite some time and recent developments have only underlined its importance, bringing a new emphasis on the subject" (Valenti, 2007, p. 530). Many new initiatives relating to IC have been articulated as major policy imperatives in a context of perceived threats to social cohesion and human rights. Such policy discourse has been constructed against a backdrop of rising levels of diversity, increased interconnectivity and more pronounced forms of human mobility (Beck, 2011; Mansouri, 2017; Wiater, 2008). A number of international agencies involved in diversity governance have started to 
explore, even advocate for, new approaches and policies aimed at overcoming the supposed shortcomings of previous policies and approaches to diversity governance (Abdallah-Pretceille, 2006; Cantle, 2012; Taylor, 2012). In this context, the CoE's white paper, Living Together as Equals in Dignity (Council of Europe, 2008), and a series of documents produced by UNESCO (UNESCO, 2006, 2009, 2010a, $2010 \mathrm{~b}, 2013$ ) have been particularly influential in framing the debates within various policy circles. These documents, and subsequent reports from other inter-state agencies, share the core premise that the intercultural approach, in contrast to other approaches to migration and diversity, offers the basis for a new peace-building framework geared towards "managing cultural diversity based on shared values and respect for common heritage, cultural diversity and human dignity" (Byram et al., 2009, p. 26). The intercultural approach, in this regard, is characterised as encompassing "the acquisition of knowledges, skills and attitudes-particularly the capacity for reflection and the self-critical disposition for life in culturally diverse societies" (Council of Europe, 2008, p. 94).

Within the international institutional setting, IC is increasingly assumed to provide the practical foundations for achieving and sustaining social peace and intercultural understanding through creating an attachment to core national values that transcend the confines of one's own cultural heritage to the exclusion of all others. Indeed, one of the core premises of IC is to provide the requisite tools for promoting social cohesion intra-nationally and peace internationally, as it emphasises contact, dialogue and meaningful exchange as fundamental principles for convivial co-existence. This key intercultural ethos which is linked to social cohesion is defined in the CoE's white paper as denoting:

the capacity of a society to ensure the welfare of all its members, minimising disparities and avoiding polarisation. A cohesive society is a mutually supportive community of free individuals pursuing these common goals by democratic means. (Council of Europe, 2008, p. 5)

This definition echoes "the redefinition of citizenship as a plural (pluralist) concept is an essential part of the intercultural discourse, in view of opening new horizons and ways for the practice of participatory and deliberative democracy at local, national, European and international level, from the city up to the EU and to other international institutions. This approach provides opportunities to all to exercise the same citizenship rights in the inclusive city" (Bekemans et al., 2007, p. 13). This citizenship-making approach (Zapata-Barrero, 2019a) is the core focus of the IC approach, which emphasises the centrality of individual rights and social cohesion in governing diversity within and across nations.

\section{UNESCO and UNU's Approach to IC}

As the oldest specialised agency within the UN system, UNESCO "sees education, social and natural science, culture and communication as the means to a far more ambitious goal: to build peace in the minds of men. In this context, the promotion of intercultural dialogue is one of the most pressing concerns of the organisation" 
(Valenti, 2007, p. 534). IC and the management of cultural diversity have indeed become key to UNESCO activities; they not only affect UNESCO's important work in the education and cultural spheres, but also shape its agendas for social transformations and its approach to the sustainable development goals (SDGs) agenda. In fact, one of UNESCO's main strategic goals is related to safeguarding cultural diversity and encouraging dialogue among cultures and civilisation, an objective that was emphasised even more within the broader SDGs agenda. Although UNESCO plays a role in nine of the UN's sixteen SDGs, it particularly highlights the interconnecting values of inclusivity, integration and universality, as hallmarks of the new SDG agenda (UNESCO, 2010b; UNESCO, 2017b).

Building on the foundational work of the CoE, UNESCO's work in the IC space adopts a human rights-based approach to cultural diversity emphasising "the need for tolerance and respect for peoples in the world through the inclusion of human rights principles in the school and the curriculum" (2006, p. 7).

Whilst these policy articulations do envisage contact, exchange and learning as key foundations for positive change, how these aims can be operationalised, implemented and assessed remains largely confused and imprecise. The challenge does not only apply to the broad notion of IC in the socio-political sphere, but also to key sectoral domains, most notably governance and education. In a number of UNESCO's key documents (UNESCO, 2006; UNESCO, 2017a; UNESCO, 2017b), the dynamic and evolving aspects of diversity are described in terms of key intercultural notions, most notably equity, dialogue and exchange. As such, IC is approached as facilitating understanding of, respect for and dialogue between different cultural groups and individuals. To this end, IC is described in this policy literature as a:

dynamic concept and refers to evolving relations between cultural groups. It has been defined as 'the existence of interaction of diverse cultures and the possibility of generating shared cultural expressions through dialogue and mutual respect'. Interculturality presupposes multiculturalism and results from 'intercultural' exchange and dialogue on the local, regional, national or international level. (UNESCO, 2006, p. 8)

This statement is relevant to two key areas. Firstly, it highlights the dynamic, relational and transformative nature of IC and its emphasis on shared values and expressions based on dialogue and respect. In many ways, these are common traits of the intercultural approach that cut across disciplinary fields and areas of public policy. Secondly, and perhaps more importantly, the UNESCO approach to IC emphasises an organic relationship to multiculturalism that is described as a prerequisite condition of the successful pursuit of intercultural initiatives. Here, we note that the complementarity of the multicultural and the intercultural, rather than their supposed oppositional juxtaposition, is being developed not only at the theoretical level but also in terms of empirical realities as reported in recent research (Mansouri \& Modood, 2020).

More broadly, and in a series of interrelated reports and manifestos, UNESCO $(2006,2009,2010 b, 2013,2017 b)$ has taken up the challenge of attempting to clarify further the meaning of IC through policy statements and guidelines designed to provide a framework for its incorporation into policy and practice, most notably in 
educational settings. Though much of the focus of UNESCO has been on pursuing IC through educational interventions, it is worth noting here the conceptual assumptions underpinning the various UNESCO reports and statements relating to IC. In this regard, UNESCO emphasises three key aspects of IC, namely, that the world is increasingly interconnected, that intercultural relations are key to preventing conflict, and that an IC-inspired approach to socio-economic inequalities will ensure successful sustainable development outcomes. In its world survey of ICD, UNESCO reaffirms its view that IC, and in particular ICD, are needed to accommodate:

the growth of this interconnectedness and interdependence [which] has also provoked divisive agendas and identity-related tensions that seek to fray the bonds of solidarity within societies and undermine peace and security. Violence and extremism have grown to alarming levels. Breaking the cycle of violent conflict is fundamental to efforts to achieve sustainable development across a complex and rapidly changing world. The need for dialogue, tolerance, respect and mutual understanding among different cultures has never been so crucial. (UNESCO 2017a, p. 10)

This reflects a growing recognition of the capacity of IC to address a host of key development and security concerns that have plagued the international community, particularly in the last two decades. Indeed, and as part of UNESCO's 2017 global survey on ICD, a more contextual definition has emerged, one that reflects prior philosophical assumptions, but also reveals new empirical crosssectoral imperatives. This nuanced definition identifies four interrelated key elements characterising the IC approach:

Context is crucial to defining and applying intercultural dialogue. Intercultural dialogue is a necessary environment for social cohesion and peace, and is instrumental in achieving related goals. Intercultural dialogue is increasingly recognized for its contribution to maintaining peaceful societies and preventing conflict. Intercultural dialogue is a wide-ranging concept and multi-stakeholder engagement is key to ensuring its implementation. (UNESCO, 2017a, p. 7)

These elements can be summarised as the importance of context, the necessity of IC for social cohesion, the importance of IC's role in conflict prevention and its multidimensional nature. More interesting in the definition coming out of this report are the enabling factors identified, which include favourable policy frameworks and an inclusive approach to participation in intercultural processes. The latter, in particular, reflects the approach articulated within the UN 2030 agenda of the SDGs, which provide an important platform for the intercultural approach to cut across sectors as a tool for realising inclusion, peace and development. Critically for UNESCO, the 2030 agenda recognises that "sustainable development cannot be achieved without peace and security" and it commits to intercultural understanding, mutual respect and "an ethic of global citizenship and shared responsibility” (UNESCO, 2010b, p. 3). SDG 16 (on peace, justice and strong 
institutions) in particular "commits the international community to preventing all forms of violence and to promoting peaceful, just and inclusive societies free from fear and violence, with accountable and inclusive institutions at all levels" (UNESCO, 2010b, p. 3), a goal to which UNESCO sees itself uniquely positioned to contribute and promote.

From UNESCO's point of view, the UN 2030 SDG agenda reflects its historical commitment to promote culture and cultural diversity as enablers for social peace, justice and development. The intercultural approach, in this context, becomes a critical tool for pursuing "social transformations for peaceful, inclusive and rights-based societies" (UNESCO, 2010b, p. 1). Again, from a broader narrative perspective, UNESCO prioritises IC as a condition that can enable positive social change based on a deep respect for diversity as a core human right ideal. For example, and in the context of the SDG agenda, UNESCO affirms that "sustainable development cannot be achieved without peace and security" and commits to intercultural understanding, mutual respect and "an ethic of global citizenship and shared responsibility" (UNESCO, 2017b, p.3). Here, the conditionality of intercultural understanding for pursuing the overall global development agenda is clearly articulated within broader interdependencies and interlinkages of the cultural, social, economic and security fields.

Not completely dissociated from UNESCO's overall agenda and its approach to IC, the UNU "consists of a globally dispersed set of research and training institutes, is a global think tank and postgraduate teaching organisation headquartered in Japan... [and its] mission is to contribute to good governance, cultural diversity, democracy and human rights through a better understanding of cultural mobility and diversity in the context of globalisation" (Nair, 2013, p. 101). Like UNESCO, the UNU views IC in particular as an essential tool for bridging cultural difference and fostering intercultural understanding and transnational solidarity. Despite these overlapping agendas with UNESCO's foundational work on IC, many of the papers produced from UNU and its various global think tanks have also provided interesting explorations of the context-specific nature of IC. Indeed, much of the UNU policy literature highlights how the concept of IC differs across different jurisdictions (i.e. member-state, context-specific interpretations), as well as how these different interpretations reflect different dynamics in power relations among the various local stakeholders. In this context, Bello (2013, p. 3) observes:

the concept and the practice of 'Intercultural Dialogue' vary across UN Member States. For each of them, this expression brings with it a particular interpretation of who are subjects of this dialogue, which parties should be involved in its implementation, and what is its final aim. These different understandings of 'Intercultural Dialogue' have been the basis of its implementation by the states involved. This suggests that, instead of an 'Intercultural Dialogue', different 'Intercultural Dialogues' are emerging from the different implementation activities put in place.

The plurality of interpretations of IC in the UNU approach outlined above risks creating unhelpful confusion as to the precise meaning and assumptions underpinning the intercultural approach. But, paradoxically, this variety of conceptions of 
and approaches to IC at the state level is also potentially a source of contextual richness that may sustain efforts to achieve peace and security within and across societies. The emergence of UNU specialised institutes on cultural diversity and IC reflects one of the many platforms that the UN system employs to promote IC between member states. Another related platform is the UN Alliance of Civilisations, launched in 2004 as a UN Secretary General initiative dedicated to promoting IC in the aftermath of the $9 / 11$ terrorist attacks and the growing discussions about civilisational clashes. Perhaps the distinguishing feature of these UN-led initiatives is the prominent role attributed to civil society organisations in promoting IC and fighting bigotry, discrimination and intolerance. This macro-orientation of IC and intercultural relations more broadly reflects the concerns of the international community at the turn of the millennium but also stands in sharp contrast to how IC was approached, justified and conceived of within the EU around the same time. European concerns, as will be discussed below, were more about the internal dynamics of a growing diversity that was perceived to be adding to social fissures because of failing integration policies that neglected the critical role of intercultural contact, local engagement and mutuality.

\section{The Emerging Intercultural Policy Debate in Europe ${ }^{1}$}

This section focuses on the emergence of the intercultural approach within Europe and then will focus more specifically on the impact of the European initiatives around intercultural cities. IC began to be widely discussed a little over decade ago, when the EU declared the Year of Intercultural Dialogue in 2008 and incorporated it into its agenda (Berry, 2018; Evans \& Weber, 2017). The EU was quick to link IC to core European values, such as human rights, democracy and a culture of peace and dialogue (Bekemans, 2012; Council of Europe, 2008; European Commission, 2008b; Vidmar-Horvat, 2012). Yet, surprisingly the founding document of the European Year of Intercultural Dialogue (EYID, 2008) itself contains not just one but three different definitions of IC: firstly, as a cross-state strategy to foster better understanding between member states and support greater cooperation within a social market economy with common values; secondly, as a cross-regional strategy to enable the EU to make its voice better heard in the world and to forge effective partnerships with countries in its neighbourhood, thus extending a zone of stability, democracy and common prosperity beyond the EU and increasing the well-being and security of European citizens and all those living in the EU; thirdly, as cultural exchange among people within the EU, leaving open that individual cross-cultural relations can operate both among EU citizens and among people from non-European cultures or so-called third-country nationals. The first interpretation has driven the mechanisms to promote European identity by fostering good relations among EU citizens. Yet, surprisingly,

\footnotetext{
1 This section is largely based on Sect. 1, Chapter 2 of R. author A Zapata-Barrero (2019a) last publication.
} 
the second and third orientations have not been widely taken up in discourse nor in practice. Indeed, the CoE's white paper on intercultural dialogue summarises these three strands, stating that IC represents:

an open and respectful exchange of views between individuals, groups, with different ethnic, cultural, religious and linguistic backgrounds and heritage on the basis of mutual understanding and respect. It operates at all levels within societies, between the societies of Europe and between Europe and the wider world. (Council of Europe, 2008, p. 10-11)

This spatial configuration of IC remains unchanged today and indeed reflects the focus of this paper in examining its multi-scale orientation. The pursuit of IC into Europe was contextually justified as part of the EU's response to the combined effects of the successive enlargements and the consequent increased mobility. This growth of the European territorial jurisdiction is compounded by old and new migratory flows, more significant exchanges with the rest of the world and increased interactions between European citizens and all those living in the EU who bring to the mix various cultures, languages, ethnic groups and religions (Ecotec, 2009). The socio-political context within the EU is such that the geographic enlargement, deregulation of employment laws and accelerating globalisation increased the "multicultural" (in descriptive terms) character of many countries, adding to the number of languages, religions and ethnic and cultural backgrounds. The EYID 2008 promoted the principle that Europe's great cultural diversity represents a unique advantage and encouraged all those living within its territory to explore its rich cultural heritage and learn from different cultural traditions (Ecotec, 2009). The overall objectives of the EYID were to promote IC as a process that would strengthen respect for cultural diversity and promote harmonious co-existence of different cultural identities and beliefs. Essentially, the EYID sought to increase the mutual understanding between peoples with different cultural and religious backgrounds, leading to increased respect and tolerance. The evaluative report we take as the main source (Ecotec, 2009) signals that this was to be achieved through a range of activities, which, in practice, appear to have been predominantly centred on cultural, educational and media-related activities but could also encompass activities in the workplace and leisure spaces. Themes addressed through these activities included migration and integration, multilingualism and interfaith dialogue. In this context, IC was about changing social attitudes through the process of cultural sharing and learning with a strong emphasis on awareness raising and a critical engagement with diversity. These initiatives were driven by an increase in social fissures involving diverse cultural groups as well as securitised national agendas in the wake of the global war on terror. Increased discrimination, lack of public support for diversity and the weakening of EU values were also part of the reasoning. Not surprisingly, the main objectives of this European initiative included shifting away from older diversity governance policies, most notably multiculturalism, with its support for group claims towards IC and its emphasis on individual contact and civic nationalism. This orientation will be further examined below in the context of the European initiative around intercultural cities. 


\section{The CoE's Distinctive Approach to IC: The City Framework and the Resource-Based Approach to Diversity Governance ${ }^{2}$}

The CoE was one of the first institutions to create a bridge between the global and the local application of IC, presenting it for the first time as an alternative narrative and policy tool vis-à-vis multiculturalism. The $\mathrm{CoE}$ framed the new intercultural discourse in ways that went further than the notion of diversity as conflict contained within earlier global meanings of IC's political roots. This new European counternarrative has seen IC emerge as policy rather than politics, to be applied at the city level, with a distinct approach to diversity governance and intercultural relations. It includes a different understanding and application of policy intervention strategies, incorporating new notions related to social innovation, creativity and transformation, as well as solidarity and cohesion.

Following the release of the 2008 white paper, IC began to penetrate cultural policy domains within Europe, with the $\mathrm{CoE}$ seemingly convinced that this was one of the best channels of IC, together with education and a focus on young people. The link between the EYID and the ICC project, a joint action of the $\mathrm{CoE}$ and the European Commission, was particularly strong, offering a coherent response to the important urban agenda. The foreword to the ICC launch, written by the mayor of The Hague and president of Eurocities, Jozias van Aarsen, stated that:

Cities play a key role in terms of facilitating and supporting intercultural dialogue, promoting mutual understanding and acceptance, and overcoming barriers between different groups. They bring together different stakeholders at the local level and have a wide range of experience and knowledge to share regarding dialogue between cultures. (Eurocities, 2009, p. 2)

The task carried out by the ICC programme since 2008 has contributed substantially to this local lens of IC in Europe with a strong and unambiguous focus on the city. In fact, and as the quote below shows, the ICC mantra has been that the future of cities will be decided by how diversity is managed:

One of the defining factors that will determine, over coming years, which cities flourish and which decline will be the extent to which they allow their diversity to be their asset, or their handicap. Whilst national and supra-national bodies will continue to wield an influence it will increasingly be the choices that cities themselves make which will seal their future. (Council of Europe, 2008, p. 22)

This city network strategy (at the time of writing ICC has reached more than 135 cities all over the world) is quite particular to Europe (for example, the Québécois approach is nationally based rather than local $)^{3}$ and has been supported by research evidence promoting IC through the avenue of cities rather than states (Wood \& Landry, 2008; Zapata-Barrero, 2015). Since the launch of ICC,

\footnotetext{
2 This section is based on Sect. 2, Chapter 2 of Author 1's (2019a) and some parts of Sect. 3 (pp 26-28).

3 See Bouchard's (2015) contractual philosophy (Zapata-Barrero, 2017a).
} 
a practical step-by-step guide has served as the main document to frame the first internal debates among local policy makers, and an ICC index is being applied across Europe and further afield (Mexico, Rabat, Montreal, Hamamatsu in Japan and cities in Australia and New Zealand) to benchmark its implementation (see https://www.coe.int/en/web/interculturalcities).

This index provides valuable primary information on how the intercultural policy paradigm is defined through ten core dimensions. These dimensions constitute a comprehensive range of areas of intervention for ensuring conditions to foster good relations among people from different backgrounds, including national citizens. These dimensions include assessment of city functions through an "intercultural lens" (education, public domain, housing and neighbourhoods, public services and civic administration, business and the economy, sport and the arts); urban safety; mediation and conflict resolution; languages; media strategy; establishing an international policy for the city; evidence-based approach; intercultural awareness training; welcoming newcomers; and intercultural governance (including participation and representation).

The central argument of the ICC index is that the contact-based approach of IC is an essential social integration policy (Guidikova, 2015) and consequently it needs to be considered as an important driver for the socialisation process, citizenship-making (Zapata-Barrero, 2019a) and culture-making (Sarmento, 2014, p. $615)$ for all. The CoE's operational definition of IC is based on dialogue promotion in cities. In terms of deeper conceptual framing, IC is defined in the white paper as:

a process that comprises an open and respectful exchange of views between individuals and groups with different ethnic, cultural, religious and linguistic backgrounds and heritage, on the basis of mutual understanding and respect. (CoE, 2008, p. 9)

IC, in this context, requires individuals to have the freedom and ability to express themselves, as well as the willingness and capacity to listen to the views of others and be open to changing one's views. This reflects both the relational as well as the transformative orientations of the intercultural approach.

Along similar lines, the CoE's (2011) Living Together paper sets out the ways in which "peaceful co-existence" can be achieved, strengthening the link between freedom and diversity. The CoE identifies seventeen "guiding principles" for living together. These mainly revolve around legal rights that apply equally to all, with an emphasis on citizenship and participation, in which people retain their distinctive cultural heritage, possibly hyphenated identities intersecting along nationality and/or faith. The $\mathrm{CoE}$ also argues for early voting rights for migrants and for respectful leadership. The cities in the ICC program are viewed as key actors facilitating IC. This document again recognises that today, towns and cities are home to a large majority of Europeans. Thus, it is within these parameters that encounters happen between people of different faiths, cultures and ethnic identities. 
Another indicator of the particular relevance of IC to cities is the Eurofund project CLIp ("European Network of cities for local integration policies for migrants"), ${ }^{4}$ launched in September 2006, which included a module on "intercultural policies and intergroup relations" (Borkert et al., 2007; Lüken-Klaßen \& Heckmann, 2010). This comes alongside the UN (2015) report that stated that by 2050 , the majority of the world's population will be living in cities, and human mobility and migration between urban areas will be central. How these cities approach diversity will also be central to their economic development and their place in a global context. The CoE, through this initiative, articulates a view of IC as a cohesion promoter and solidarity creator. From the very beginning, a focus on promoting contact rather than separation, on working towards immigrants' inclusion and on devising policies concentrating on immigrants within the basic mainstream structure of public services, was put forward by the $\mathrm{CoE}$ as an integration policy that reflected these views. Such intercultural policy was also theorised in other parts of Europe as an inclusion policy with the central purpose of preventing socio-economic exclusion. ${ }^{5}$ The first theoretical articulation came from Wood and Landry (2008), whose urban intercultural philosophy influenced the CoE's ICC initiative.

The new interpretation of IC that informed the $\mathrm{CoE}$ came mainly from urban, social management and business studies but also from social psychology and a burgeoning literature in education studies (Zapata-Barrero, 2019a, p. 29) and only recently started to penetrate policy debates on diversity and immigration studies. The proponents of this new approach brought with them a concept of diversity advantage (Zapata-Barrero, 2019a), ${ }^{6}$ which was absent from previous narratives. The scholarly debate behind this notion stresses the resource-based approach to diversity. Following Faist's (2009) analysis of the diversity category, it suggests people be considered both in terms of their rights and in terms of what they can do and are able to achieve. This notion of productive diversity as a potential resource and a driver of opportunities contrasts with the predominant global view of diversity as conflict, as we have discussed above. The CoE's ICC programme made a competitive call in March 2015 for cities to select the best practical initiatives for diversity advantage challenges. The way they defined the diversity advantage was broad but still fits the focus here as it states the following:

Recognising that diversity is not a threat - it can bring competitive benefits for businesses, organisations and communities if managed competently and in the spirit of inclusion ... [and] Embracing diversity is not a gimmick for the branding of a business, organisation or city but a philosophy of governance, management and decision making. (Council of Europe, 2015, p. 3)

\footnotetext{
${ }^{4}$ See more information and publications at the following website: https://www.eurofound.europa.eu/ about-clip

5 See Borkert et al. (2007); Caponio and Ricucci (2015); Lüken-Klaßen and Heckmann (2010). This last work provides an overview as to how the debate was introduced by EU institutions.

6 The concept of diversity advantage has been introduced by the UK think tank Comedia directed by Wood (2004), mainly inspired by Zachary's (2003) seminal work.
} 
Cantle's $(2008,2012)$ various interventions provide further insight into the European approach to IC, illustrating a less constructivist focus and drawing on a much more social and cosmopolitan strand of IC. This latter notion adds to the European debate with a double function of being a policy strategy that seeks to solve but also to prevent determinate urban areas from becoming "conflict zones" rather than "contact zones". From the very beginning, the focus on promoting contact rather than separation, on focusing on as much incorporation as possible, and on devising policies concentrating on immigrants within the basic mainstream structure of public services, was put forward as a community cohesion policy that responded to contemporary public views. Cantle's (2012) report on the British government's concern about local social disturbances in the northern towns of Bradford, Burnley and Oldham in May to July 2011 shows that these events reflect, at least partially, the failure of British multicultural policy. In his book Community Cohesion, Cantle (2008) explicitly articulates these ideas and argues against the promotion of "parallel lives" of communities that have little in common in terms of shared values and no meaningful contact with each other. Diversity, in this context, acquires a Janus face that can go from extreme otherness and conflict to understanding and togetherness. Left unattended, diversity can generate negative social outcomes: social disturbances, racism, xenophobia, discrimination, inequality, unbalanced power relations, unethical treatment, human rights infringement, stereotypes, prejudices and lack of confidence, among others (Meer et al., 2016). Today, all these variables can be encapsulated under the broad framework of "social conflict". Perhaps, little is known about societal benefits of diversity in the public imaginary, but most people can easily identify the problems when images of riots, social fissures and outright conflicts are shown across different media platforms (Mansouri \& Vergani, 2018). This double-plugged reality and understanding drive the view of the $\mathrm{CoE}$ and its ICC programme. In this sense, IC does not only have a reactive dimension as when it is used as a post-conflict intervention for reducing social conflicts, but, more importantly, it has a proactive dimension, able to foster new forms of cohesion, social innovation, creativity and cross-cultural solidarity.

The methodological approach to cohesion articulated in the ICC programme as described above accounts for IC in horizontal terms. It argues that IC is inherently multidimensional and complex, without any pre-categorisation of the individuals and groups involved. It thus breaks away the dualistic view of the population between a majority/us/national/citizen and a minority/other/diverse/ immigrant. In this case, it is in line with the post-ethnic and post-racial view of diversity, reflecting the core ethos of the intercultural approach to diversity management (Zapata-Barrero, 2019a).

A number of other European policy document stress the importance of cities as key actors for diversity management and cohesion promotion (e.g. European Commission, 2008a, b, 2015). One of the first EU political documents making this "city turn" explicit was the European Ministerial Conference on Integration (Zaragoza, 15-16 April 2010), ${ }^{7}$ held under the Spanish Presidency, which underlined once

\footnotetext{
7 Established by the European Foundation for the Improvement of Living and Working Conditions, the Council of Europe and the City of Stuttgart (www.eurofound.europa.eu/ areas/populationandsociety/clip. htm).
} 
again the central role of local authorities in implementing intercultural and integration programmes. Specifically, the final declaration of the conference concluded:

Considering that cities and their districts are privileged areas for fostering intercultural dialogue and for promoting cultural diversity and social cohesion, it is important for local governments to develop and obtain capacities to better manage diversity and to combat racism, xenophobia and all forms of discrimination. (European Commission, 2010, p. 7)

Finally, a key date and policy document relevant to this discussion is 21 January 2015, when the Committee of Ministers of the CoE adopted for the first time an explicit endorsement of the ICC approach. This recommendation states that the ICC approach to diversity and inclusion remedies the shortcomings of past policies and enables the realisation of the advantages of diversity. The Committee of Ministers acknowledges that cities are laboratories for policy innovation which can make an important contribution to social cohesion by adopting the intercultural approach at the city level. ${ }^{8}$ Together, all the documents shaping the European view of IC share the substantial idea that IC is better implemented at the sub-state level. The reasons for this are directly related to the fact that diversity management is optimally served by an administration that is close to the everyday lives of ordinary citizens. These are the grounds for considering intercultural citizenship as local, with some implications for citizenship studies, where there is a gradual shift from a nationally based to an urban-based conception of citizenship. All these European documents, despite their differences in emphasis, convey the same message about the critical link between IC and cities. Urban IC, therefore, becomes an optimal policy paradigm for local managers of migrationrelated diversity. It is much more closely connected to ordinary citizens' concerns and best able to accommodate the specificities of local policies in terms of relevance, pragmatism and proximity (Zapata-Barrero, 2018). As shown by some recent studies, local approaches to IC are better for dealing with economic crises (Caponio \& Donatiello, 2017), super-diverse societies (Hadj and Geddes, 2017) and the transnational realities of most people living in contemporary cities (Zapata-Barrero, 2018).

To summarise the key points contained in these policy documents, IC speaks to the everyday lived reality of culturally and religiously diverse cities with all their fluidity and creativity, as well as the everyday challenges of living with difference. This also means that IC highlights a sense of place as a vital element in identity formation-and this can include the place where people live and feel a sense of belonging through everyday practices in their neighbourhood (Hellgren, 2018). This is why most of the literature take for granted that public spaces play a central role in IC, as they ensure the best conditions for face-to-face intercultural contact and authentic interpersonal relations (Zapata-Barrero, 2019a).

\footnotetext{
${ }^{8}$ For more information about this recommendation and the activities linked to it, see the following website: https:/www.coe.int/en/web/culture-and-heritage/-recommendation-on-intercultural-integration
} 
Cities bear the main responsibility for ensuring that culturally diverse societies are open societies, in which people belonging to different cultural groups-including recent arrivals and temporary residents - can feel at home and make their own contributions, in their own way, to the city's overall social development. Thus, local authorities play a key role in the process of building peaceful relations between different people and in reducing tensions, which often arise along ethnic, religious and cultural fault lines. This perhaps reflects the assumptions behind the CoE's (2011) ICC programme, which demonstrates, through many case studies, that cities can use diversity as an asset for individual and social development. ${ }^{9}$

\section{Conclusion: Towards a More Multi-scale Framing in Interculturalism}

The first purpose of this article was to review the historical emergence of IC and examine its multi-scale foundation and application, arguing that the re-direction, from global politics to local policy, needs a clear analytical distinction to avoid taking for granted arguments and theoretical paradigms related to its core assumptions. The main argument advanced here is that if this multi-scale application of IC involves an uncritical transfer of meanings from the global to the local agenda, it may risk contributing to greater conceptual fuzziness and policy confusion.

A key implication of this analysis for future studies related to diversity and migration is the need for multi-scale framing. This means that approaches to IC and diversity matters need to reflect contextualised multi-scale understandings and applications that avoid simplistic generalisations and methodological/epistemological confusions. This analytical clarification of scale of meanings is key to understanding the plurality of applications of IC that today inform diversity governance debates.

Finally, this analysis presented in this article aims to avoid a view of diversity challenges in our cities as essentially civilisational conflicts manifesting at a local scale or to view religious diversity as reproducing in our streets global inter-religious and inter-ethnic conflicts. Such a conflict-based view diversity is exactly what IC seeks to disrupt in order to move towards proactive, transformative approaches to intercultural relations. The uncritical projection of the global politics of IC onto the local level can polarise societies along religious and cultural terms and territorialise conflicts in ways that undermine the precise ethos of IC. The shift of IC's sphere of application has meaningful societal consequences that allow for more nuanced understandings of its new role. This delineation of IC's multi-scale capacity will avoid unnecessary confusion of its semantic core, which remains focussed on the need to promote meaningful contact and interpersonal relations within socio-culturally plural societies (Zapata-Barrero, 2019a).

\footnotetext{
9 See, among others, reports on diverse cities: London (Bagwell et al., 2012), Lewisham (a borough of London) (Brecknock et al., 2007) and Helsinki (Comedia, 2010). Regarding Barcelona, a more recent critical article has appeared in Zapata-Barrero (2017b)
} 
Funding Open Access funding provided thanks to the CRUE-CSIC agreement with Springer Nature.

Open Access This article is licensed under a Creative Commons Attribution 4.0 International License, which permits use, sharing, adaptation, distribution and reproduction in any medium or format, as long as you give appropriate credit to the original author(s) and the source, provide a link to the Creative Commons licence, and indicate if changes were made. The images or other third party material in this article are included in the article's Creative Commons licence, unless indicated otherwise in a credit line to the material. If material is not included in the article's Creative Commons licence and your intended use is not permitted by statutory regulation or exceeds the permitted use, you will need to obtain permission directly from the copyright holder. To view a copy of this licence, visit http://creativecommons.org/licen ses/by/4.0/.

\section{References}

Abdallah-Pretceille, M. (2006). Interculturalism as a paradigm for thinking about diversity. Intercultural Education, 17(5), 475-483. https://doi.org/10.1080/14675980601065764

Bagwell, S., Evans, G., Witting, A., \& Worpole, K. (2012). Public space management: Report to the intercultural cities research programme. London: Cities Institute, London Metropolitan University. https://rm.coe.int/CoERMPublicCommonSearchServices/Display DCTMContent?document $\mathrm{Id}=09000016803009 \mathrm{c} 0$

Beck, U. (2011). Multiculturalism or cosmopolitanism: How can we describe and understand the diversity of the world? Social Sciences in China, 32(4), 52-58. https://doi.org/10.1080/02529 203.2011.625169

Bekemans, L. (2012). Intercultural dialogue and multi-level governance in Europe: A human rights based approach. P.I.E. Peter Lang.

Bekemans, L., Karasinska-Fendler, M., Mascia, M., Papisc, A., Stephanou, C. A., \& Xuereb, P. G. (Eds.). (2007). Intercultural dialogue and citizenship translating values into actions a common project for Europeans and their partners. Marsilio Publising.

Bello, V. (2013). Intercultural dialogue or intercultural soliloquies? Policy Report No. 01/08. Barcelona: United Nations University Institute on Globalization, Culture and Mobility (UNU-GCM).

Berry, S. E. (2018). Aligning interculturalism with international human rights law: "Living together" without assimilation. Human Rights Law Review, 18(3), 441-471.

Borkert, M., Bosswick, W., Heckmann, F., \& Lüken-Klaßen, D. (2007). Local integration policies for migrants in Europe. Official Publications European Communities VIII.

Bouchard, G. (2015). Interculturalism: A view from Quebec. University of Toronto Press.

Brecknock, R., Caust, M., Howell, A., \& Landry, C. (2007). Knowing Lewisham, Bournes Green: Comedia. Available at: www.coe.int/t/dg4/cultureheritage/culture/cities/Publication/Lewisham. pdf

Byram, M., Barrett, M., Ipgrave, J., Jackson, R., \& Garcia, M. C. M. (2009). The autobiography of intercultural encounters: Context, concepts and theories. Strasbourg: Council of Europe.

Cantle, T. (2008). Community cohesion: A new framework for race and diversity. Palgrave Macmillan.

Cantle, T. (2012). Interculturalism: The new era of cohesion and diversity. Palgrave Macmillan.

Caponio, T. and Donatiello, D. (2017). Intercultural policy in times of crisis: Theory and practice in the case of Turin, Italy. Comparative Migration Studies, 5(13).

Caponio, T., \& Ricucci, R. (2015). Interculturalism: A policy instrument supporting social inclusion? In R. Zapata-Barrero (Ed.), Interculturalism in Cities (pp. 20-34). Edward Elgar Publishing.

Cardno, C. (2018). Policy document analysis: A practical educational leadership tool and a qualitative research method. Kuram Ve Uygulamada Ĕ̆itim Yönetimi, 24(4), 623-640. https://doi.org/10.14527/ kuey.2018.016

Comedia. (2010). Helsinki is an open and intercultural city. Stroud: Comedia.

Council of Europe. (2008). White paper on intercultural dialogue 'living together as equals in dignity.' Council of Europe.

Council of Europe. (2011). Living together - combining diversity and freedom in 21st century Europe. Strasbourg: Council of Europe. Available at: www.coe.int/t/dg4/highereducation/2011/KYIV\% 20WEBSITE/Report\%20on\%20diversity.pdf 
Council of Europe. (2015). Diversity advantage challenge. Strasbourg: Council of Europe. Available: https://edoc.coe.int/en/living-together-diversity-and-freedom-in-europe/6555-diversity-advantagechallenge-selected-initiatives.html. (Accessed 10/10/2019).

Delafenetre, D. G. (1997). Interculturalism, multiracialism and transculturalism: Australian and Canadian experiences in the 1990s. Nationalism and Ethnic Politics, 3(1), 89-110.

Ecotec. (2009). Evaluation of the European year of intercultural dialogue 2008 final report. Birmingham: Ecotec. Available at: https://ec.europa.eu/culture/sites/culture/files/intercultural-dialogue-yearevaluation-2009_en.pdf

Elias, A., \& Mansouri, F. (2020). A systematic review of studies on interculturalism and intercultural dialogue. Journal of Intercultural Studies, 41(1). https://doi.org/10.1080/07256868.2020.1782861

Elias, A., Mansouri, F., \& Sweid, R., (2020). 'Public attitudes towards multiculturalism and interculturalism in Australia'. Journal of International Migration and Integration. https://link.springer.com/artic le/10.1007/s12134-020-00784-z

Eurocities. (2009). Intercultural cities - A journey through 23 European cities. Council of Europe.

European Commission. (2008a). Intercultural dialogue in Europe. Available at: https://ec.europa.eu/ culture/policy/strategic-framework/intercultural-dialogue_en.htm

European Commission. (2008b). Highlights of the European year of intercultural dialogue. Available at: https://eur-lex.europa.eu/legal-content/EN/TXT/?uri=URISERV\%3A129017

European Commission. (2010). European ministerial conference on integration, Zaragoza, 15-16 April. Available at: https://ec.europa.eu/migrant-integration/librarydoc/declaration-of-the-europ ean-ministerial-conference-on-integration-zaragoza-15-16-april-2010.

European Commission. (2015). Recommendation CM/Rec(2015)1 of the Committee of Ministers to Member States on intercultural integration. Available at: https://search.coe.int/cm/Pages/result_ details.aspx? ObjectID=09000016805c471f

European Year of Intercultural Dialogue. (2008). Local government and interculturalism: The contribution of the Greek local authorities to the intercultural dialogue today. Ministry of Interior and Ministry of Foreign Affairs, Hellenic Republic. Available at: https://ec.europa.eu/citizenship/ pdf/doc891_en.pdf

Evans, M. D., \& Weber, A. (2017). Council of Europe manuals: Human rights in culturally diverse societies. Nijhoff.

Faist, T. (2009). Diversity - A new mode of incorporation? Ethnic and Racial Studies, 32(1), 171190. https://doi.org/10.1080/01419870802483650

Gagnon, A., \& Iacovino, R. (2016). Interculturalism and multiculturalism: Similarities and differences. In N. Meer, T. Modood, \& R. Zapata-Barrero (Eds.), Multiculturalism and interculturalism: Debating the dividing lines (pp. 104-132). Edinburgh University Press.

Guidikova, I. (2015). Intercultural integration: A new paradigm for managing diversity as an advantage. In R. Zapata-Barrero (Ed.), Interculturalism in cities: Concept, policy and implementation (pp. 136-151). Edward Elgar Publishing.

Hadj, A. L., \& Geddes, A. (2017). Managing superdiversity? Examining the intercultural policy turn in Europe. Policy and Politics, 45(4), 493-510.

Hashemi, N. (2016). Toward a political theory of sectarianism in the Middle East: The salience of authoritarianism over theology. Journal of Islamic and Muslim Studies, 1(1), 65-76.

Hellgren, Z. (2018). Class, race - and place: Immigrants' self-perceptions on inclusion, belonging and opportunities in Stockholm and Barcelona. Ethnic and Racial Studies. https://doi.org/10.1080/ 01419870.2018 .1532095

Huntington, S. P. (1993). The clash of civilizations? Foreign Affairs, 72(3), 22-49.

Lashta, E., Berdahl, L., \& Walker, R. (2016). Interpersonal contact and attitudes towards Indigenous Peoples in Canada's prairie cities. Ethnic and Racial Studies, 39(7), 1242-1260.

Levrau, F., \& Loobuyck, P. (coords.) (2018), Multiculturalism-interculturalism. Comparative Migration Studies, 6. https://comparativemigrationstudies.springeropen.com/multiculturalism-inter culturalism

Lüken-Klaßen, D., \& Heckmann, F. (2010). Intercultural policies in European cities. Report, European network of cities for local integration policies for migrants (CLIP). Dublin: Eurofound.

Mansouri, F., \& Vergani, M. (2018). Intercultural contact, knowledge of Islam, and prejudice against Muslims in Australia. International Journal of Intercultural Relations, 66, 85-94.

Mansouri, F. (2017). Interculturalism at the crossroads: Theory, policy and practice. UNESCO Publishing. 
Mansouri, F., \& Lobo, M. (Eds.). (2011). Migration, citizenship, and intercultural relations: Looking through the lens of social inclusion. Ashgate Publishing Ltd.

Mansouri, F., Elias, A., \& Sweid, R. (2017). The doing diversity project: Revitalizing multiculturalism through intercultural dialogue and deliberative interventions. Deakin University Publishing.

Mansouri F., \& Modood, T. (2020). The complementarity of multiculturalism and interculturalism: Theory backed by Australian evidence, ethnic and racial studies. https://doi.org/10.1080/01419 870.2020 .1713391

Meer, N., Modood, T., \& Zapata-Barrero, R. (Eds.). (2016). Multiculturalism and interculturalism: Debating the dividing lines. Edinburgh University Press.

Nair, P. (2013). The United Nations University Institute on Globalization, Culture and Mobility (UNU-GCM) in Barcelona: Mission and vision. Contributions to Science, 9, 101-106. https:// doi.org/10.2436/20.7010.01.168

Orton, A. (2016). Interfaith dialogue: Seven key questions for theory, policy and practice. Religion, State \& Society, 44(4), 349-365. https://doi.org/10.1080/09637494.2016.1242886

Omotosho, M. (2014). Managing religious conflicts in Nigeria: The inter-religious mediation peace strategy. Africa Development, XXXIX(2), 133-151.

de Perini, P. (2020). The changing scope of intercultural dialogue in EU Mediterranean policy. Mediterranean Politics, 25(5), 600-626. https://doi.org/10.1080/13629395.2019.1605757

Roe, E. (1994). Narrative policy analysis: Theory and practice. Duke University Press.

Sarmento, C. (2014). Interculturalism, multiculturalism, and intercultural studies: Questioning definitions and repositioning strategies. Intercultural Pragmatics, 11(4), 603-618.

Solano-Campos, A. T. (2013). Bringing Latin America's "interculturalidad" into the conversation. Journal of Intercultural Studies, 34(5), 620-630.

Solano-Campos, A. T. (2016). Models of diversity in the Americas: Avenues for dialogue and crosspollination. In N. Meer, T. Modood, \& R. Zapata-Barrero (Eds.), Multiculturalism and interculturalism: Debating the dividing lines. Edinburgh University Press.

Taylor, C. (2012). Interculturalism or multiculturalism? Philosophy \& Social Criticism, 38(4-5), 413-423.

Tubino, F., \& Sinnigen, J. H. (2013). Intercultural practices in Latin American nation states. Journal of Intercultural Studies, 34(5), 604-619.

UNESCO (United Nations Educational Scientific and Cultural Organisation). (2006). Guidelines on intercultural education. UNESCO.

UNESCO. (2009). Investing in cultural diversity and intercultural dialogue. UNESCO.

UNESCO (United Nations Educational Scientific and Cultural Organisation). (2010a). Education for intercultural understanding. UNESCO.

UNESCO (United Nations Educational Scientific and Cultural Organisation). (2010b). Moving forward the 2030 Agenda for Sustainable Development. UNESCO.

UNESCO (United Nations Educational Scientific and Cultural Organisation). (2013). Intercultural competences: Conceptual and operational framework. UNESCO.

United Nations. (2015). World urbanization prospects: The 2014 revision. United Nations.

UNESCO (United Nations Educational Scientific and Cultural Organisation). (2017a). UNESCO survey of intercultural dialogue: Analysis of findings. UNESCO.

UNESCO (United Nations Educational Scientific and Cultural Organisation). (2017b). UNESCO moving forward the 2030 Agenda for Sustainable Development. Paris: UNESCO. https://en.unesco.org/creativity/sites/creativity/files/247785en.pdf

Valenti, S. (2007). The mainstreaming of intercultural dialogue in the Council of Europe, OSCE and UNESCO. In Léonce. Bekemans, Maria Karasinska-Fendler, Marco Mascia, Antonio Papisca, Constantine A. Stephanou, \& Peter G. Xuereb (Eds.), Intercultural Dialogue and Citizenship Translating Values into Actions A Common Project for Europeans and Their Partners. Marsilio Publising.

Vertovec, S. (2007). Super-diversity and its implications. Ethnic and Racial Studies, 30(6), 1024-1054.

Vidmar-Horvat, K. (2012). The predicament of intercultural dialogue: Reconsidering the politics of culture and identity in the EU. Cultural Sociology, 6(1), 27-44.

Walton, P. (2012). Intercultural dialogue and the emerging Mediterranean: Realigning the Anna Lindh Foundation strategy. In S. Calleya, \& M. Wohlfeld (Eds.), Change and Opportunities in the Emerging Mediterranean (pp. 274-299). Mediterranean Academy of Diplomatic Studies. 
Wiater, P. (2008). Intercultural dialogue, living together as equals in dignity. White Paper, Committee of Ministers. Council of Europe.

Wood, P. (2004). The intercultural city reader. Comedia.

Wood, P., \& Landry, C. (2008). The intercultural city: Planning for diversity advantage. Earthscan.

Yazbeck Haddad, Y., \& Fischbach, R. (2015). Interfaith dialogue in Lebanon: Between a power balancing act and theological encounters. Islam and Christian-Muslim Relations, 26(4), 423-442.

Zachary, P. (2003). The diversity advantage: Multicultural identity in the new world economy. Westview.

Zapata-Barrero, R. (Ed.). (2015). Interculturalism in cities: Concept, policy and implementation. Edward Elgar Publishing.

Zapata-Barrero, R. (2017a). Interculturalism in the post-multicultural debate: A defence. Comparative Migration Studies, 5(14), 1-23.

Zapata-Barrero, R. (2017b). Multi-level intercultural governance in Barcelona: Mainstreaming comprehensive approach. International Review of Administrative Sciences, 83(2), 247-266.

Zapata-Barrero, R. (2018). Transnationalism and interculturalism: Overlapping affinities. In J. E. Fossum, R. Kastoryano, \& B. Siim (Eds.), Diversity and Contestations over Nationalism in Europe and Canada (pp. 89-122). Palgrave Macmillan.

Zapata-Barrero, R. (2019a). Intercultural citizenship in the post-multicultural era. Sage.

Zapata-Barrero, R. (2019b). Guest editorial: Methodological interculturalism: Breaking down epistemological barriers around diversity management. Ethnic and Racial Studies, 42(3), 346-356. https://doi.org/10.1080/01419870.2019.153

Publisher's Note Springer Nature remains neutral with regard to jurisdictional claims in published maps and institutional affiliations. 